article with a good deal of interest, and I do not at all question your feeling that the discussion of the possibilities of the gift while the organization is yet forming can hardly result in embarrassment, and ought to materially help the trustees. I quite agree with you that there ought to be found a better plan than the permanent shouldering of the burden of a large research establishment, and particularly of one devoted to one department of science if this is to prevent the reaching of a helping hand in other directions, as time brings their needs to light. And I quite agree with you that it would be unfortunate in the long run if the fund, which, though large, is not unlimited, were to be invested in any project which the Government or any of the better equipped existing institutions could undertake, perhaps with the temporary aid that you suggest. To come into the field of any of the Government bureaus that have ample publication funds would, as you well say, result in little if any good, and might actually do harm.

In a nutshell, while I have not given the matter enough thought to warrant the publication of a suggestion even, I have supposed that the opportunity of the Institution lies in the day-to-day and year-to-year use of its funds for the furtherance of the work of any earnest worker in need of aid - whether an individual or an institution. This presupposes the conservation of any sum not needed at any given time, against the day of its real need, with an unusual amount of earnest search for the best place of using it at any given time-for there is no doubt that the most worthy individuals and institutions that could use it are likely to be least forward in applying for aid, either from pride or modesty.*

\section{WM. TRelease.}

* The above letter was not written for publication, and was received before the current discussion had been begun, but is printed with the consent of the writer.
Pressure of official duties makes it impossible for me to write at present an article on the Carnegie Institution. You are, however, at liberty to quote me to the effect that it would be inadvisable for the institution to erect either a geophysical laboratory at Washington or to acquire the Marine Laboratory at Wood's Hole. I think that the policy should be followed of promoting geophysical researches along lines not specifically treated by governmental institutions. Men of parts and ability should be encouraged by grants, under such restrictions as to continuance from year to year as would produce results. Many permanent officials should be discouraged; it is difficult to get rid of a man when he once holds office, no matter if it is evident to every one that his mental powers and physical energy are waning. I do not believe that there should be any large laboratory built by the institution, believing that more effective work and better results could be obtained by subsidizing laboratories now in existence. In short, I hold that the activities of the institution should be kept well in hand under the control of the central commission, so that the rapidly shifting phases of research may receive timely attention through the abandonment of some lines and the taking up of others. This would make the Carnegie Institution in a way the center of the spirit of scientific investigation of the United States.

\section{A. W. Greely.}

\section{SCIENTIFIC BOOKS.}

Animal Activities. A First Book in Zoology. By Nathaniel S. French, Ph.D. New York, Longmans, Green \& Co. 1902. Pp. $\mathrm{xxi}+262$, with illustrations.

Elementary Zoology. By Vernon L. KeLLOGG, M.S. New York, "Henry Holt \& Co. 1901. Pp. $\mathrm{xv}+492$, with illustrations. 
Nature Study and Life. By Cufton F. Hodae, Ph.D. Boston, Ginn \& Co. 1902. Pp. $x v+514$, illustrated.

The teaching of the sciences in schools is justified largely by the unequaled possibilities they afford for the development of the powers of observation, but in addition to this primary quality they are by no means lacking in others of great pedagogic importance. Judiciously treated, they may serve also in the training of the powers of deduction and, furthermore, may possess distinct utilitarian advantages not only by imparting information of the kind generally spoken of as 'useful,' but also by awakening in the mind of the child an intelligent interest in nature and a desire to discover nature's laws.

Three elementary text-books of zoology (one of them really pertaining to the wider field of biology) have recently appeared, and it is proposed briefly to consider to what extent each is possessed of the qualities just mentioned. The first of these books is by Dr. Nathaniel French and is entitled 'Animal Activities' (Longmans, Green \& Co.). The volume opens with introductory chapters devoted to instructions for the collection and preservation of material for study and to the exposition of some general physiological principles, and then proceeds to an examination of the structure and activities of crickets and grasshoppers, the pupil being guided toward the observations desired by questions. Then follows an interrogational guide to other insects, then to spiders and then to the crayfish and other crustacea, after which the remaining animal groups are considered in succession, beginning with the protozoa.

Subjected to the observational test, the book gives a decided and, on the whole, a satisfactory response, although the criticisms may justly be made that frequently the guiding questions are too leading and that occasionally the pupil is tempted toward decidedly inaccurate observations. But with the deductive and utilitarian tests the reactions are disappointing, contrary to what might be expected from the chosen title. Not that the desired qualities are entirely lacking, but that they are not more equally developed in proportion to the training afforded in observation. A competent teacher who would supply the deficient qualities might use the book with advantage, though it must be confessed that in the treatment of some of the groups it fails to reach the standard which should be demanded in a high school text, which it is intended to be. It is unfortunate that the sources from which some familiar illustrations are borrowed are not acknowledged.

The second book, 'Elementary Zoology' (Henry Holt \& Co.), by Professor Vernon L. Kellogg, is of a more thorough character and attains much more perfectly the proper highschool standard. It starts with directions, to a certain extent stated interrogatively, for the study of the toad, the crayfish, the amoba and paramœcium and the hydra, presenting the general principles which may be deduced from each, and then proceeds to the study of each of the great groups of the animal kingdom, beginning with the protozoa. One or more species of each group are selected for study and a clear and interesting account is given of other important members of the group. Then follow brief but generally excellent chapters on natural selection, parasitism, coloration, distribution and similar topics, and finally there are added chapters, again excellent, on the methods for collecting, rearing and preserving material.

The book is throughout deserving of praise. To the observational test it responds most satisfactorily and the author shows an admirable appreciation of the proper perspective in the selection of points to be especially emphasized. It furnishes, perhaps, too many deductions ready made, but this failing is to a large extent compensated by the suggestiveness of much of the descriptive portion of the text and of the chapters treating the more general topics. Especial attention is not drawn to the directly practical side of zoology, although reference is made to many forms of economic importance, but the interesting descriptions of habits and life-histories which occur abundantly throughout the book and the wealth of striking illustrations can hardly fail to arouse in the pupil a deep and lasting interest in 'Nature's children' and to stimulate a. 
desire for more intimate acquaintance with them.

The third book, 'Nature Study and Life' (Ginn \& Co.), by Professor C. F. Hodge, belongs to a different class than the other two, being intended for the teacher rather than for the pupil and for the teacher of younger classes. It may be said at once that it is a book which will be welcomed not only by such teachers, but by all who are called upon to find occupation for the busy little fingers and active, eager minds of children. It is a guide to nature study in its best sense and, as President Stanley Hall properly points out in an introduction, it is entirely free from that effeminization which too often detracts from the usefulness of nature study books.

It presents an abundance of just the kind of material a child should study, the fullest and yet most simple methods for facilitating its observation, admirable suggestions for arousing the reasoning faculties concerning it, a wealth of practical application of the knowledge acquired, and running through the whole there is manifest a love of nature for nature's self which cannot fail to impart itself to both teacher and pupil. To describe in detail the contents of the volume is out of the question, but a citation of the headings of some of the chapters will give some idea of its scope: 'Insects of the Household,' 'Insects of the Garden,' 'Beneficial Insects,' 'Elementary Botany,' 'Home and School Gardens,' 'The Propagation of Plants,' 'Our Common Birds,' 'The Domestication of Wild Birds,' 'Elementary Forestry,' 'Aquaria,' 'Flowerless Plants.' And all these and other topics are treated so clearly and suggestively that he who runs may read and have plenty of food for thought when he sits down to rest. Indeed the book possesses a special charm from the freshness and enthusiasm of the author's style, qualities, which, when combined with fascinating photographic reproductions, make the reader forget that he is reading a book and not listening to the author in person discoursing interestingly and convincingly from the fullness of his knowledge.

The information which the book imparts and the training it aims to give are the infor- mation and training which educate. For, as the author rightly says: "To do our duty by our neighbors we need a large body of knowledge of the common things that surround the home," and the acquisition of a knowledge of our duty by our neighbors, using that term in the broader Scriptural sense, and an idea of how best to fulfill that duty is the aim of education. Would that this book were in the hands of every teacher of children and every school trustee throughout the land!

\section{J. P. McM.}

Irrigation Farming. By L. M. WILcox. New York, Orange Judd Co. 1902. Pp. 494, pl. 1, figs. 113.

The first edition of this book appeared in 1895. Since that date irrigation farming has rapidly extended in both arid and humid regions and many improvements have been made in methods, as a result of a better understanding of the principles involved. The author in this revised edition in a measure takes cognizance of these advances by adding a number of new sections and four new chapters, namely, seepage and drainage, electricity and irrigation, irrigation in humid climates, and winter irrigation. It is to be regretted, however, that the revision has not been more thorough and included the correction of the numerous inaccurate, and in some cases absurd, statements regarding certain scientific features of the subject, which are left in this edition just as they were in the original edition. The follow. ing, relating to the acids of the soil, is an example:

In all soils we find two essential acids, known scientifically as humic and ulmic. The first is the acid in the humus, or vegetable and animal matter, in the soil. As animal life is built by vegetable matter, it must eventually turn back to vegetable matter. Ulmic acids are those that exude from the roots of some plants. We should remember that nitrogen is the costliest of all plant foods and the most difficult to retain in the soil, and plants must have it, for it corrects this humic acid in the plant as well as in the soil. The ulmic acids are seldom in sufficient quantity to do harm. But the humic acids when shut off from the proportions of nitrogen or potash-both alkalis -become too concentrated, or the dead microbes 